\title{
Preclinical Lipid Profile Studies of a Classical Ayurvedic Preparation, Siddha Makardhwaja (SMD), after Chronic Administration to Male Sprague-Dawley Rats
}

Md. Mamun Sikder*, Tasniya Nahiyan Zulfiquar, Imtiaj Hossain Chowdhury, Khadija Akter, Umma Hafsa Asha, Epsheta Haque, Proshanta Chakraborty, M. S. K. Choudhuri

Department of Pharmacy, Jahangirnagar University, Savar, Dhaka-1342, Bangladesh

*Corresponding author: Sikder MM, Department of Pharmacy, Jahangirnagar University, Savar, Dhaka-1342, Bangladesh; E-mail: shikder1753@gmail.com Received: October 03, 2017; Accepted: March 21, 2018; Published: March 28, 2018

\begin{abstract}
Siddha Makardhwaja (SMD) is a classical Ayurvedic formulation markedly used as a traditional medicine in the rural population for various purposes, such as a stimulant, tonic, and rejuvenator. The present study was conducted to evaluate the effect of conventionally prepared SMD on different lipid-profile parameters in experimental animals, for providing scientific database for its logical use in clinical practice. Acute toxicity tests were conducted to determine the LD50 of the drug. To find out the effect of chronic administration of SMD on serum lipid profile, it was administered chronically to the male Sprague-Dawley rats at a dose of $40 \mathrm{mg} / \mathrm{kg}$ for 28 days. During the lipid profile study, we found out the following: There is a statistically significant $(p=0.042)$ decrease in the triglyceride content of the serum of the male rat [21.71\% decrease]. There is a [21.65\%] increase in the LDL level of the serum of the male rat; the increase, though not significant, was prominent $(p=0.122)$. There is a statistically significant $(p=0.042)$ decrease in the VLDL level of the serum of the male rat $[21.71 \%$ decrease]. There is a statistically significant $(p=0.016)$ decrease in the HDL level of the serum of the male rat [20.36\% decrease]. There is a statistically significant $(p=0.041)$ increase in the Cardiac Risk Ratio $[(\mathrm{CRR})=$ Total cholesterol/HDL ratio] of the male rat $[23.45 \%$ increase]. There is a statistically significant $(p=0.026)$ increase in the Castelli's Risk Index II [(CRI II = LDL/HDL ratio] of the male rat [51.50\% increase]. There is a statistically significant $(p=0.041)$ increase in the Atherogenic Coefficient (AC) of the male rat $[40.39 \%$ increase].
\end{abstract}

Keywords: Ayurvedic preparation; Lipid profile; Cardiac Risk Ratio; Atherogenic Index of Plasma; Atherogenic Coefficient

\section{Introduction}

Ayurvedic medicines have reputation as decent and effective remedies for a number of diseases [1]. Currently, the World Health Organization (WHO) has officially recognized and recommended large-scale use of herbal (Unani and Ayurvedic) remedies, particularly in the developing countries, as an alternative system of medicine, to deliver health-care services at the primary health-care level [2]. According to WHO, an estimated 1.5 billion people of the world are now getting treatment with these medicines [3]. They also have a good safety profile [4].

Siddha Makardhwaj is an ancient Indian multipurpose Ayurvedic medicine that acts as an alternative, stimulant, tonic, and rejuvenator (Table 1). Its regular use prevents the wrinkling of skin and greying of hair due to old age. Siddha Makardhwaj is also an effective natural aphrodisiac; however, it should be taken only under strict medical supervision [5-9].

A natural aphrodisiac, this herbal product is known for calming cardiac muscles as well. It contains gold particles, or Swarna Bhasma, which is known to have many good benefits for the human body. Ayurveda states that gold, in its element and medicinal formulation, can improve intelligence and sharpen memory [5-9].

Siddha Makardhwaj is included in the Bangladesh National Formulary of Ayurvedic Medicine 1992 (approved by the Government of Bangladesh vide Ministry of Health and Family Welfare Memo No. Health-1/Unani- 2/89/(Part-1) 116 dated 3-6-1991) [5].

\section{Materials and Methods}

\section{Drugs, chemicals, and reagents}

For the toxicological study, SMD was collected from Sri Kundeswari Aushadhalaya Limited, Chittagong. Ketamine injection was purchased from ACI Pharmaceuticals Limited, Bangladesh. All other reagents, assay kits, and chemicals used in this work were purchased from Human GmbH, Wiesbaden, Germany.

\section{Experimental animals}

Six- to eight-week-old male Sprague-Dawley rats bred and maintained at the animal house of the Department of Pharmacy, Jahangirnagar University, were used in the toxicological experiment. These animals were apparently healthy and weighed 70-80 g. The animals were housed in a well-ventilated, clean experimental animal house, under constant environmental and adequate nutritional conditions throughout the period of the experiment. They were fed with rat chow prepared according to the formula developed at the Bangladesh Council of Scientific and Industrial Research (BCSIR). Water was provided ad libitum, and the animals were maintained at $12 \mathrm{~h}$ day and $12 \mathrm{~h}$ night cycle. All experiments on rats were carried out in absolute compliance with the ethical guide for care and use of laboratory animals approved by the Ethical Review Committee, Faculty of Life Sciences, Department of Pharmacy, Jahangirnagar University.

\section{Experimental design}

\section{Acute toxicity study}

The acute oral toxicity test was performed following the guidelines of Organization for Economic Co-operation and Development (OECD) for testing of chemicals with minor modification (OECD Guideline 425) [10]. Sixteen male mice (30-35 g body weight) were divided into four groups of four animals each. Different doses $(1,000,2,000,3,000$, and $4,000 \mathrm{mg} / \mathrm{kg}$ ) of the experimental drug (SMD) were administered by a stomach tube. The dose was divided into two fractions and given within $12 \mathrm{~h}$. Then all the experimental animals were observed for mortality and clinical toxicity signs (general behavior, respiratory pattern, cardiovascular signs, motor activities, reflexes, and changes in 
Citation: Sikder MM, Zulfiquar TN, Chowdhury IH, Akter K, Asha UH, et al. (2018) Preclinical Lipid Profile Studies of a Classical Ayurvedic Preparation "Siddha Makardhwaja (SMD)" after Chronic Administration to Male Sprague-Dawley Rats. Biol Med (Aligarh) 10: 439. doi:10.4172/0974-8369.1000439

Page 2 of 4

skin and fur texture) at 1,2,3, and $4 \mathrm{~h}$ and thereafter once a day for the next three days following SMD administration.

\section{Chronic toxicity studies}

Prior to the experiment, the rats were randomly divided into 2 groups of 8 animals each. One group was treated with SMD and another was used as a control. The control animals were administered with distilled water with the same volume as the drug-treated group for 28 days. After acclimatization, the Ayurvedic medicinal preparation was administered to the rats by intragastric syringe between $10 \mathrm{a} . \mathrm{m}$. and 12 a.m. daily throughout the study period. All experiments on the rats were carried out in absolute compliance with the ethical guide for care and use of laboratory animals. The experiment animals were marked carefully on the ear, which helped identify a particular animal. By using identification mark, responses were noted separately for a particular period prior to and after the administration.

\section{Collection of blood samples and preparation of serum}

At the end of 28 days of treatment, after $18 \mathrm{~h}$ fasting, blood samples were collected from the posterior vena cava of the rats, which were anesthetized with ketamine (500 $\mathrm{mg} / \mathrm{kg}$ body weight, intraperitoneal), and transferred into plain sample tubes immediately for serum generation. The blood was then centrifuged at 4,000 g for $10 \mathrm{~min}$ using a benchtop centrifuge (MSE Minor, England). The supernatant plasma samples were collected using a dry Pasteur pipette and stored in a refrigerator for further analyses. All analyses were completed within 12 $\mathrm{h}$ of sample collection.

\section{Determination of lipid profile parameters}

Lipid profile studies involved analysis of parameters such as triglyceride (TG) level, determined by GPO-PAP method [11]; total cholesterol (TC) level, determined by CHOD-PAP method [12]; LDL-cholesterol level, determined by CHOD-PAP method [13]; and HDL cholesterol level, determined by CHOD-PAP method [14]. The absorbance of all the tests was determined using HumaLyzer, Model No-3500 (Human GmbH, Wiesbaden, Germany). Serum LDL and VLDL cholesterol concentrations were calculated using the Friedewald equation [15] as follows:

i. LDL cholesterol $(\mathrm{mg} / \mathrm{dl})=$ Total cholesterol $-($ HDL cholesterol - Triglyceride / 5).

ii. VLDL cholesterol $(\mathrm{mg} / \mathrm{dl})=$ Triglyceride $/ 5$.

The serum non-HDL cholesterol concentration was determined as reported by Brunzell [16]:

Non-HDL cholesterol $=$ Total cholesterol - HDL cholesterol.

The atherogenic indices were calculated as follows:

Cardiac Risk Ratio (CRR) $=$ TC / HDL [17].

Castelli’s Risk Index (CRI-II) = LDL-C / HDL [18].
Atherogenic Coefficient $(\mathrm{AC})=(\mathrm{TC}-\mathrm{HDL}-\mathrm{C}) / \mathrm{HDL}-\mathrm{C}[19]$.

Atherogenic Index of Plasma (AIP) $=\log (\mathrm{TG} / \mathrm{HDL})[20]$.

\section{Statistical analysis}

The data were analyzed using an independent sample t-test with the help of SPSS (Statistical Package for Social Sciences) Statistics 11.5 package (SPSS Inc., Chicago, Illinois). All values were expressed as mean \pm SEM (standard error of the mean) and $p^{\star} \leq 0.05, p^{* *} \leq 0.01$, and $p^{* *} \leq 0.001$ were taken as the level of significance.

\section{Results}

\section{Acute toxicity study}

The drug (SMD) administered up to a high dose of $80 \mathrm{ml} / \mathrm{kg}$ produced no mortality. Thus the LD50 value was found to be greater than $80 \mathrm{ml} / \mathrm{kg}$ body weight. The animals did not manifest any sign of restlessness, respiratory distress, general irritation, or convulsion. Since SMD is in the clinical use for treatment of diarrhea, dysentery, and irritable bowel syndrome for many years, a limit test was performed in the acute oral toxicity study. According to the OECD test guideline 425 , when there is information in support of low or nontoxicity and immortality nature of the test material, then the limit test at the highest starting dose level ( $80 \mathrm{ml} / \mathrm{kg}$ body weight) was conducted. There were no mortality and toxicity signs observed at $80 \mathrm{ml} / \mathrm{kg}$ body weight. Therefore, it can be concluded that SMD when administered at single dose is nontoxic and can be used safely in oral formulations.

\section{Chronic lipid profile studies}

\section{Effect of SMD on the lipid profile of male rats}

During the lipid profile study, we found the following: There is a statistically significant $(p=0.042)$ decrease in the triglyceride content of the serum of the male rat $[21.71 \%$ decrease] (Table 2). There is a negligible [1.55\%] decrease in the total cholesterol content of the serum of the male rat, which was statistically not at all significant $(p=0.785)$ There is a $21.65 \%$ increase in the LDL level of the serum of the male rat; the increase, though not significant, was prominent $(p=0.122)$. There is a statistically significant $(p=0.042)$ decrease in the VLDL level of the serum of the male rat $[21.71 \%$ decrease $]$. There is a statistically significant $(p=0.016)$ decrease in the HDL level of the serum of the male rat $[20.36 \%$ decrease]. There is a $12.59 \%$ increase in the non-HDL level of the serum of the male rat; the increase, though not significant, was prominent $(p=0.249)$.

\section{Effect of SMD on the atherogenic indices of male rats}

There is a statistically significant $(p=0.041)$ increase in the Cardiac Risk Ratio [(CRR) = Total cholesterol/HDL ratio] of the male rat $[23.45 \%$ increase] (Table 3 ). There is a statistically significant $(p=0.026)$ increase in the Castelli's Risk Index II [(CRI II $=$ LDL/ HDL ratio] of the male rat $[51.50 \%$ increase]. There is a statistically

\begin{tabular}{|c|c|c|c|}
\hline SI. No. & Ingredient & Plant part & Botanical/zoological or Calyx name \\
\hline 1. & Gandhaka & & Purified and processed sulfur \\
\hline 2. & Parada & & Purified and processed mercury \\
\hline 3. & Swarna Bhasma & & Gold Bhasma \\
\hline 4. & Rakta karpasa kusuma & Flower & Gossypium herbaceum \\
\hline 5. & Kumari & Leaf & Aloe vera \\
\hline
\end{tabular}

Table 1: Name of the ingredients/herbs used in the preparation of Siddha Makardhwaja 
Citation: Sikder MM, Zulfiquar TN, Chowdhury IH, Akter K, Asha UH, et al. (2018) Preclinical Lipid Profile Studies of a Classical Ayurvedic Preparation "Siddha Makardhwaja (SMD)" after Chronic Administration to Male Sprague-Dawley Rats. Biol Med (Aligarh) 10: 439. doi:10.4172/0974-8369.1000439

Page 3 of 4

\begin{tabular}{|c|c|c|c|c|}
\hline Parameters & Control & SMD & $p$ values & \% Change \\
\hline Cholesterol & $64.3750 \pm 2.49955$ & $63.3750 \pm 2.58386$ & 0.785 & $\downarrow 1.55$ \\
\hline Triglycerides (TG) & $38.0000 \pm 3.18479$ & $29.7500 \pm 1.57831$ & ${ }^{*} 0.042$ & $\downarrow 21.71$ \\
\hline HDL & $27.6250 \pm 1.59169$ & $22.0000 \pm 1.28174$ & ${ }^{*} 0.016$ & $\downarrow 20.36$ \\
\hline LDL & $28.8750 \pm 2.51735$ & $35.1250 \pm 2.83749$ & 0.122 & $\downarrow$ \\
\hline VLDL & $7.6000 \pm 0.63696$ & $5.9500 \pm 0.31566$ & $* 0.042$ & $\downarrow$ \\
\hline Non-HDL & $36.7500 \pm 2.57564$ & $41.3750 \pm 2.85943$ & 0.249 & $\downarrow 21.71$ \\
\hline
\end{tabular}

$\uparrow:$ increase, $\downarrow$ : decrease; $p^{*} \leq 0.05, p^{* *} \leq 0.01, p^{* * *} \leq 0.001$

Table 2: Effect of SMD on the lipid profile of rat serum

\begin{tabular}{|c|c|c|c|c|}
\hline Parameters & Control & SMD & $p$ values & $\%$ Change \\
\hline CRR & $2.3849 \pm 0.15794$ & $2.9442 \pm 0.19255$ & ${ }^{*} 0.041$ & $\uparrow 23.452$ \\
\hline CRI-II & $1.0912 \pm 0.13507$ & $1.6532 \pm 0.18018$ & ${ }^{*} 0.026$ & $\uparrow 51.503$ \\
\hline$A C$ & $0.1328 \pm 0.04556$ & $0.1319 \pm 0.03458$ & 0.988 & $\uparrow 0.678$ \\
\hline AIP & $1.3849 \pm 0.15794$ & $1.9442 \pm 0.19255$ & ${ }^{*} 0.041$ & $\uparrow 40.386$ \\
\hline
\end{tabular}

$\uparrow$ : increase, $\downarrow$ : decrease; $p^{*} \leq 0.05, p^{* *} \leq 0.01, p^{* * *} \leq 0.001$.

Table 3: Effect of SMD on the atherogenic indices of rat serum

significant $(p=0.041)$ increase in the Atherogenic Coefficient (AC) of the male rat $[40.39 \%$ increase]. There was no change noticed in the Atherogenic Index of Plasma (AIP) of the male rat.

\section{Discussion}

Ayurvedic medicines have achieved greater importance as an alternative to conventional therapy. To enhance the safe use of plant-based medicines, one should take into account their historical applications on humans and animals as well as the toxicity evaluation of the medicinal herbs and their active components [21]. Although significant advances have been made in the development and application of in vitro toxicity assays, in vivo safety evaluation remains the most useful tool for detecting target-organ toxicity [22]. The rat has been the species of choice for the majority of preclinical toxicology studies. Recent findings revealed that rat and mouse are suitable models for early safety assessment since earlier identification of preclinical toxicities are generally predictive of human toxicity and could save time, money, and effort [23].

\section{Effect of SMD on the lipid profile of male rats}

Reduced serum HDL cholesterol is a risk factor for cardiovascular disease [24] and is often found in hypertension [25]. So, in the present study, the low serum HDL cholesterol level, recorded for the treated groups, is suggestive of the cardiotoxic effect of the drug. High levels of plasma LDL cholesterol are risk factors for cardiovascular disease and often accompany hypertension and obesity [26-28]. In this study, significantly higher plasma LDL and significantly lower VLDL cholesterol levels were observed in the animals treated with SMD.

\section{Effect of SMD on the atherogenic indices of male rats}

In this study, SMD augmented almost all the atherogenic indices except AIP. The increase in Cardiac Risk Ratio (CRR), Castelli's Risk Index-II (CRI-II), and Atherogenic Coefficient (AC) was statistically highly significant. Atherogenic indices are strong indicators of the risk of heart disease: the higher the value, the higher the risk of developing cardiovascular problems and vice versa [29-30]. Low atherogenic indices are protective against coronary heart disease [31].

\section{Conclusion}

From the above experiment, it can be concluded that SMD should not be administered chronically at a higher dose as it increases LDL and atherogenic indices and decreases HDL level. Further studies should be done at reduced administered dose.

\section{Acknowledgment}

The authors are thankful to Focused Research on Ayurvedic Medicine and Education (F.R.A.M.E) Laboratory, Department of Pharmacy, and all the faculty members and technical staffs of the Department of Pharmacy, Jahangirnagar University, for their kind cooperation. We would like to express our special thanks to $\mathrm{Mr}$. Shafiqul Islam for ensuring a constant supply of animals and the proper maintenance and care of these animals throughout the experimental period.

\section{References}

1. WHO (1977) Regional Office for the Western Pacific Seminar on the Use of Medicinal Plants in Health Care. Final Report, Tokyo, Japan, pp. 13-17.

2. WHO (2002) WHO Launches the First Global Strategy on Traditional and Alternative Medicine. Press Release, WHO/38.

3. WHO (1999) Consultation Meeting on Traditional Medicine and Modern Medicine: Harmonizing the Two Approaches. World Health Organization, Geneva (document reference (WP) TM/ICP/TM/001/RB/98-RS/99/ $\mathrm{GE} / 32(\mathrm{CHN}))$, Geneva, Switzerland.

4. Ernst E (2002) Ayurvedic medicines. Pharmacoepidemiol Drug Saf 11(6): 455-456

5. Anonymous (2011) Bangladesh National Formulary of Ayurvedic Medicine 1992 (Approved by the Government of Bangladesh vide Ministry of Health and Family Welfare Memo No. Health-1/Unani-2/89/(Part-1) 116 dated 3-6-1991) National Unani and Ayurvedic Formulary Committee Bangladesh Board of Unani and Ayurvedic Systems of Medicine, Dhaka (2nd edn 2011).

6. Anonymous (1978) Ayurvedic Formulary of India, The (1978). Government of India, Ministry of Health and Family Welfare. Department of Health, New Delhi. Volume I, Part I, first edition, XXXVI and 324 p. (2nd edn, part I, XLVI and 488 p.).

7. Anonymous (1978) Hand Book of Ayurvedic and Herbal Medicines with Formulae: With Directory of Manufacturers and Suppliers of Plants, Equipment and Machineries, Packaging Materials and Raw Materials Suppliers. Engineers India Research Institute, Delhi, XVIII, 382 p. 
Citation: Sikder MM, Zulfiquar TN, Chowdhury IH, Akter K, Asha UH, et al. (2018) Preclinical Lipid Profile Studies of a Classical Ayurvedic Preparation "Siddha Makardhwaja (SMD)" after Chronic Administration to Male Sprague-Dawley Rats. Biol Med (Aligarh) 10: 439. doi:10.4172/0974-8369.1000439

Page 4 of 4

8. Anonymous (1978) Handbook of Domestic Medicine and Common Ayurvedic Remedies. Central Council for Research in Ayurveda and Siddha, New Delhi, $x v+v i+538$ p. (reprint 2005).

9. Anonymous (2011) Ayurvedic Formulary of India. The (2011) Government of India, New Delhi. Volume I, part 3, LXXVI and $710 \mathrm{p}$.

10. OECD Guideline (425) for the testing of chemicals (2008) Guidance Document on Acute Oral Toxicity, Environmental Health and Safety Monograph Series on Testing and Assessment, pp. 1-27.

11. Cole TG, Klotzsch SG, Namara MC (1997) Measurement of triglyceride concentration. In: Rifai N, Warnick GR, Domiminiczak MH, eds. EditionHandbook of Lipoprotein Testing. AACC Press, Washington, DC, pp. 115-126.

12. Richmond W (1973) Clin Chem 19: 1350-1356.

13. Okada M, Matsui H, Ito Y, Fujiwara A, Inano K (1998) J Lab Clin Med 132(3): 195-201.

14. Henry RJ, Winkleman JW, Cannon DC (1974) Clinical Chemistry-Principles and Technics (2nd edn). Harper \& Row Publishers, New York.

15. Friedewald WT, Levy RI, Friedrickson DS (1972) Clin Chem 18: 499-502.

16. Brunzell JD, Davidson M, Furberg CD, Goldberg RD, Howard BV, et al. (2008) J Am Coll Cardiol 51: 1512-1524.

17. Martirosyan DM, Miroshnichenko LA, Kulokawa SN, Pogojeva AV, Zoloedov VI (2007) Lipids Health Dis 6: 1.

18. Castelli WP, Abbott RD, McNamara PM (1983) Circulation 67(4): 730-734.

19. Brehm A, Pfeiler G, Pacini G, Vierhapper H, Roden M (2004) Relationship between serum lipoprotein ratios and insulin resistance in obesity. Clin Chem 50: 2316-2322.
20. Dobiasova M (2004) Atherogenic index of plasma [log (triglyceride/HDLcholesterol)]: theoretical and practical implications. Clin Chem 50: 1113-1115.

21. Mukinda JT, Syce JA (2007) J Ethnopharmacol 112: 138-144

22. Fielden MR, Kolaja KL (2008) Expert Opin Drug Saf 7: 107-110.

23. Jeffrey AK, Emily O, Megan EP, Debra B, Traci S, et al. (2010) Toxicol Pathol 38: 452-471.

24. Lewis GF, Rader DJ (2005) New insights into the regulation of HDL metabolism and reverse cholesterol transport. Circ Res 96: 1221-1232.

25. Shepherd J (1998) Identifying patients at risk for coronary heart disease: treatment implications. Eur Heart J 19: 1776-1783.

26. Lichtenstein AH, Appel LJ, Brands M, Carnethon M, Daniels S, et al. (2006) Summary of American heart association diet and lifestyle recommendations revision. Arterioscler Thromb Vasc Biol 26: 2186-2191.

27. Lichtenstein AH, Appel LJ, Brands M, Carnethon M, Daniels S, et al. (2006) Diet and lifestyle recommendations revision. A scientific statement from the American Heart Association Nutrition Committee. Circulation 114: 82-96.

28. Krauss RM, Blanche PJ, Rawlings RS, Fernstrom HS, Williams PT (2006) Separate effects of reduced carbohydrate intake and weight loss on atherogenic dyslipidemia. Am J Clin Nutr 83: 1025-1031.

29. Castelli WP, Abbott RD, McNamara PM (1983) Summary estimates of cholesterol used to predict coronary heart disease. Circulation 67(4): 730-734.

30. Brehm A, Pfeiler G, Pacini G, Vierhapper H, Roden M (2004) Relationship between serum lipoprotein ratios and insulin resistance in obesity. Clin Chem 50: 2316-2322.

31. Usoro CAO, Adikwuru CC, Usoro IN, Nsonwu AC (2006) Lipid profile of postmenopausal women in Calabar, Nigeria. Pak J Nutr 5: 79-82. 